\title{
Prolactin Modulation of Immune and Inflammatory Responses
}

\author{
Li-YuAN Yu-LeE \\ Department of Medicine, Department of Molecular and Cellular Biology, Department of \\ Immunology, and Program in Cell and Molecular Biology, Baylor College of Medicine, Houston, \\ Texas 77030
}

\begin{abstract}
Prolactin (PRL), a pituitary peptide hormone, is known to regulate diverse physiological functions via its effects on cellular processes such as proliferation, differentiation, and cell survival. All these activities are mediated by the PRL receptor (PRL-R), a member of the hematopoietin cytokine receptor superfamily. To understand PRL-dependent mitogenic signaling in $\mathrm{T}$ cells, we cloned PRL, PRL-R, one mediator of PRL signaling, signal transducer and activator of transcription (Stat) $5 \mathrm{~b}$, and a panel of PRL-inducible immediate early-response genes from $\mathrm{T}$ cells. We are employing one of these PRL-inducible genes, the transcription factor interferon regulatory factor- 1 (IRF-1), a multifunctional immune regulator gene, as a tool to understand how PRL modulates T-cell proliferative responses. In investigating regulatory events along the PRL-R/Janus activating kinase (JAK)/Stat/IRF-1 signaling pathway, we show that Stat factors can activate as well as inhibit IRF-1 promoter activity and that cross talk between Stat and nuclear factor $(\mathrm{NF}) \kappa \mathrm{B}$ signaling pathways also regulates IRF-1 expression. In understanding how signaling pathways cross talk at the IRF-1 promoter, we obtained insights into how PRL can modulate immune and inflammatory responses. These findings have much broader implications, not only for cells in the immune system but also for other PRL-responsive cells and tissues.
\end{abstract}

\section{Introduction}

Prolactin (PRL) is a 23-kDa polypeptide that is synthesized primarily in the pituitary. PRL is also synthesized and secreted by many extrapituitary tissues (Ben-Jonathan et al., 1996). Whether endocrine or autocrine, PRL exerts profound effects on a wide range of tissues, with over 300 effects described in vertebrates (Bole-Feysot et al., 1998). PRL regulates the differentiation of secretory glands, including the mammary gland, ovary, prostate, submaxillary and lacrimal glands, pancreas, and liver (for a review, see Horseman, 2001). PRL also regulates proliferation in different cell types, including mammary epithelium, pancreatic beta cells, astrocytes, anterior pituitary cells, adipocytes, and T lymphocytes (Yu-Lee et al., 1990; DeVito et al., 1992; Nanbu-Wakao et al., 2000; Horseman, 2001). We and others have cloned PRL from T lymphocytes, 
where it has been shown to promote proliferation, protect against apoptosis, and enhance cell survival (LaVoie and Witorsch, 1995; Buckley, 2001). Hence, PRL is also known as a T-cell cytokine (Yu-Lee et al., 1998; Montgomery, 2001). How pituitary or extrapituitary PRL modulates target cell function likely depends on the cell type and its stage of differentiation.

As one approach to understanding how PRL modulates T-cell proliferative responses, we cloned a panel of 26 PRL-responsive immediate early-response genes from a rat $\mathrm{T}$-lymphoma cell line, $\mathrm{Nb} 2$, induced to proliferate by PRL (Yu-Lee et al., 1990). Nb2 $\mathrm{T}$ cells express a high number of PRL receptor (PRL-R), which is a member of the hematopoietin/cytokine receptor superfamily and is exquisitely sensitive to PRL for growth (Gout et al., 1980). Several PRL-inducible genes have been extensively characterized (Stevens et al., 1995; Morris et al., 1997). We focus here on the transcription factor interferon regulatory factor-1 (IRF-1), which plays a pivotal role in multiple immune functions. In understanding the signaling pathway to the IRF-1 gene, we elucidated not only positive and negative regulation but also how various cytokine signals compete/cross talk at the IRF-1 promoter. We will highlight controversies concerning PRL's role in mediating immune, autoimmune, and inflammatory responses, then summarize the renewed interest in evaluating PRL as a hormone or cytokine involved in maintaining immune system homeostasis (Dorshkind and Horseman, 2001).

\section{Prolactin and Immune, Autoimmune, and Inflammatory Responses}

\section{A. PROLACTIN AND IMMUNE RESPONSES}

A large body of literature dating from the 1930s suggests a role of PRL and other pituitary hormones in modulating the immune system (Smith, 1930; Kooijman et al., 1996). Clinical, animal, and in vitro studies combine to suggest that PRL exhibits immunostimulatory properties (Yu-Lee, 1997). PRL has been shown to stimulate $\mathrm{T}$ cells, B cells, natural killer (NK) cells, macrophages, neutrophils, CD34+ hematopoietic cells, and antigen-presenting dendritic cells (Kooijman et al., 1996; Dogusan et al., 2001; Matera et al., 2001). However, animals with a targeted disruption of either the PRL (Horseman et al., 1997) or PRL-R (Bouchard et al., 1999) gene (knockout, or KO) suggest that PRL is not essential for normal immune system development or function. The KO animals show normal T-cell, B-cell, and NK-cell development and distribution as well as normal T-cell mitogenic responses, B-cell antibody production, and NK-cellmediated cytotoxicity (Bouchard et al., 1999). A normal immune response to Listeria infection involving innate as well as adaptive immune responses is intact in PRL-R KO mice. However, compensatory actions by other cytokines (redundancy) in these $\mathrm{KO}$ mice have not been examined. 
In Snell dwarf mice that are deficient in anterior pituitary hormones, normal immune responses were observed in animals housed separately from their wild-type littermates (Dorshkind and Horseman, 2000). In contrast, immune defects were observed only in those dwarf animals housed together with their normal littermates, which resulted in a highly stressful environment. The variable housing conditions apparently contributed to conflicting data on the effects of PRL and growth hormone (GH) on immune responses in the dwarf mice. PRL and other pituitary hormones are suggested to act as stress-adaptation molecules important in maintaining immune system homeostasis (Dorshkind and Horseman, 2001). Under stressful conditions, PRL is needed to balance the negative effects of glucocorticoids and other immune or inflammatory mediators to maintain steady-state homeostasis. This interpretation is supported by in vitro studies showing PRL's protective effect in preventing glucocorticoid-induced lymphocyte cell death (apoptosis) (LaVoie and Witorsch, 1995; Buckley, 2001) and by in vivo studies showing that PRL improves macrophage and splenocyte functions following trauma-hemorrhage and infections (Zellweger et al., 1996). A concerted effort by many laboratories is underway to evaluate the immunomodulatory activities of PRL in the context of stress, trauma, injury, inflammation, infection, and various autoimmune diseases (Matera et al., 2000; Richards and Murphy, 2000; Dorshkind and Horseman, 2001; Hooghe et al., 2001).

\section{B. PROLACTIN AND AUTOIMMUNE DISEASES}

Many autoimmune diseases are prevalent in women of childbearing age, most notably, systemic lupus erythematosus (SLE), which occurs more frequently in females than males by a 9:1 ratio. This female gender bias suggests that female hormones (e.g., PRL, estrogen (E2)) may play a role in the pathogenesis of this autoimmune disease. Pituitary PRL expression is under E2 regulation (Couse and Korach, 1999). PRL, in turn, regulates E2 receptor (ER) $\alpha$ and $\mathrm{ER} \beta$ expression in the female reproductive tissues and the mammary gland (Tessier et al., 2000). Thus, a positive regulatory loop exists between PRL and E2 action. PRL levels are higher in women than men. Elevated PRL levels have been reported in patients with SLE, multiple sclerosis, rheumatoid arthritis, psoriatic arthritis, AIDS, and prior to transplant rejection (Kanik and Wilder, 2000; Jacobi et al., 2001; Walker, 2001). Bromocriptine (BRC), a dopamine agonist that inhibits PRL release from the pituitary, can suppress autoimmune uveitis and correct T-cell and NK-cell abnormalities in patients with pathological hyperprolactinemia (Vidaller et al., 1992). BRC also suppresses SLE in some patients and reduces the number of lupus flares (Walker, 2001). Although a clear causal relationship is still lacking, these clinical data suggest that altered PRL levels may exacerbate certain autoimmune diseases. 
A better correlation between PRL and immune regulation is observed in animal models, where circulating PRL levels can be altered by hypophysectomy, BRC treatment, or genetic deletions. Hypophysectomized animals are deficient in mounting various B- and T-cell-mediated immune responses, which are restored by PRL injections. High PRL levels are found in rats with experimentally induced adjuvant arthritis or encephalomyelitis and in the NZB/NZW F1 lupus mice (Kooijman et al., 1996; McMurray, 2001). BRC treatment reduced disease symptoms and delayed lupus-related death, which results primarily from glomerulonephritis (immunoglobulin deposits) in the kidney (McMurray, 2001). Recent animal studies suggest that E2-treated transgenic animals develop a lupus-like phenotype with an expansion in autoreactive B cells (a breakdown of tolerance) and elevation in antibody production (Peeva et al., 2000; Grimaldi et al., 2001). This E2 effect requires the presence of PRL as BRC treatment reduced antibody production (Peeva et al., 2000). Interestingly, both E2 and PRL can upregulate Bcl-2 expression in B cells (Morales et al., 1999; Peeva et al., 2000; Buckley, 2001) and may account for the enhanced survival of autoreactive B cells. Together, these clinical and animal studies support a role of E2 and PRL in modulating lymphocyte functions in the context of various autoimmune diseases.

\section{PROLACTIN AND INFLAMMATORY RESPONSES}

PRL and E2 have been shown to be protective against inflammation in the context of severe trauma (Jarrar et al., 2000; Knoferl et al., 2000b). Trauma is the fourth leading cause of death in the United States (Zhu et al., 1997). Gender seems to play a role in the response to trauma. Female patients survive better than male patients in response to severe trauma (Morris et al., 1990), supporting the notion that female hormones may protect against hemorrhage and/or septic complications. In male trauma patients, a greater susceptibility to infections is correlated with a higher serum level of proinflammatory cytokines such as interleukin-6 (IL-6) (Offner et al., 1999; Oberholzer et al., 2000). In animal models, trauma-hemorrhage is associated with depressed immune functions and increased infection, morbidity, and mortality (Zellweger et al., 1996). Under this condition, PRL as well as E2 protects against trauma-hemorrhage by reducing plasma levels of corticosterone and IL-6, enhancing splenocyte proliferation and function, and increasing survival of animals to septic shock (Zellweger et al., 1996; Knoferl et al., 2000a,b). These studies show that both PRL and E2 protect against inflammation and improve dysfunctional immune responses under conditions of severe stress. A reciprocal relationship is also found between high serum corticosterone versus low PRL levels after a burn injury (Thellin et al., 2001). In this model of burn-induced stress, the low level of PRL is correlated with 
a significant increase in IL-6 production by gut enterocytes, which is accompanied by a loss of gut integrity, bacterial translocation into the circulation, and septic complications (Ogle et al., 2000).

PRL and E2 also inhibit IL-6 gene expression in female reproductive tissues (Deb et al., 1999) and bone (Manolagas, 2000). During pregnancy, IL-6 expression in the decidua is inhibited by E2 and PRL, as increases in IL-6 can lead to termination of pregnancy. Both PRL and E2 downregulate the expression of the gp130 component of the IL-6 receptor complex (Kurebayashi et al., 1997; Deb et al., 1999). In bone, IL-6 is produced by the osteoblast to regulate osteoclast differentiation and bone resorption. IL-6 is thought to contribute to bone loss during menopause (Manolagas, 2000). E2 prevents bone loss in part by inhibiting IL-6 expression in osteoblasts and bone marrow stromal cells (Girasole et al., 1992). E2 also antagonizes IL-6 function by blocking IL-6-inducible signal transducer and activator of transcription (Stat) 3 activity (Yamamoto et al., 2000). Both osteoblasts and bone marrow stromal cells express the PRL-R (McAveney et al., 1996; Goffin et al., 1999), which suggests that PRL may inhibit IL-6 expression in cells in bone marrow. These studies show that PRL and E2 can inhibit IL-6 function at multiple levels, including blocking IL-6 and IL-6 receptor gp130 expression as well as antagonizing IL-6 signaling potential.

Paradoxically, PRL and E2 contribute to hyperplasia and inflammation in the prostate (Tangbanluekal and Robinette, 1993; Leav et al., 1999; van Coppenolle et al., 2001). Transgenic mice overexpressing PRL develop enlarged prostates (Wennbo et al., 1997). Exposure of rats to PRL and E2 results in prostate inflammation, which is characterized by infiltration of lymphocytes and macrophages into the stromal compartment and of neutrophils into the lumen of the dorsolateral lobe of the prostate gland (Tangbanluekal and Robinette, 1993; Stoker et al., 1999; van Coppenolle et al., 2001). The rat dorsolateral prostate is structurally and functionally most similar to the human prostate. PRL appears to be a survival factor (Ahonen et al., 1999) and induces Bcl-2 expression in prostate epithelial cells (van Coppenolle et al., 2001). Interestingly, E2 upregulates IL-6 gene expression (Harris et al., 2000) and IL-6, in turn, induces androgen receptor (AR) gene expression as well as AR function in prostate epithelial cells (Lin et al., 2001). AR is required for PRL expression in the prostate epithelium in vivo (Nevalainen et al., 1997). Thus, a complex positive regulatory loop exists among the hormones, cytokines, and their receptors within the prostate. How these interactions promote prostate inflammation, hyperplasia, and cancer progression remains to be elucidated. Although the mechanisms involved are not known, PRL and E2 can be anti-inflammatory or proinflammatory, depending on the cell type, the tissue, and the physiological state of the organ. 


\section{PROLACTIN AND HEMATOPOIESIS}

PRL and GH play a role in stimulating the hematopoietic system (Bellone et al., 1995; Richards and Murphy, 2000). PRL enhances granulocyte/macrophagecolony stimulating factor (GM-CSF)-mediated maturation of CD34+ human hematopoietic progenitor cells into erythroid precursors in culture (Bellone et al., 1995). Pharmacologic levels of PRL increase the hematopoietic progenitors of the myeloid (colony-forming unit-granulocyte macrophage, or CFU-GM) and erythroid (blast-forming unit-erythocyte, or BFU-E) lineages in the bone marrow and spleen, during myelosuppression following treatment for HIV infection or bone marrow transplantation (Richards and Murphy, 2000). PRL also increases the number of progenitors of other immune cell lineages, including $\mathrm{T}$ cells, B cells, and NK cells (Bellone et al., 1995). In various diseases, PRL antagonizes the immunosuppressive effects of transforming growth factor-beta (TGF- $\beta$ ) (Richards et al., 1998), tumor necrosis factor alpha (TNF $\alpha$ ) (Luo and Yu-Lee, 2000), or corticosterone (LaVoie and Witorsch, 1995; Buckley, 2001) and thus may enhance recovery of the hematopoietic system. In the pregnant maternal uterus, several PRL-like proteins (PLP) interact with immune function cells. The trophoblast-derived PLP-A binds to and inhibits maternal NK cells to ensure successful fetal development (Muller et al., 1999). The placental-derived PLP-E binds to megakaryocytes and promotes their differentiation and maturation, in preparation for accelerated platelet production during pregnancy (Lin and Linzer, 1999). Thus, placental PRL-like hormones play novel roles in regulating hematopoiesis during pregnancy.

In the following section, we will consider some of the mechanisms by which PRL mediates such diverse biological responses. Our studies on PRL signaling to the master immune regulator gene IRF-1 provide some insight into how PRL activates or inhibits gene transcription. These analyses may help to elucidate how PRL can be anti-inflammatory in one tissue but proinflammatory in another or how PRL can exacerbate autoimmune diseases.

\section{Prolactin Receptor Signaling}

\section{A. PRL-R STRUCTURE AND FUNCTION}

The diverse activities of PRL are mediated by the PRL-R, which is expressed on many cell types. Several receptor forms exist, including the long (85-90 kDa) and short (42 kDa) PRL-R, which result from differential splicing of $3^{\prime}$ end cytoplasmic domain exons from a single gene (Goffin and Kelly, 1997). A naturally occurring intermediate PRL-R form $(65 \mathrm{kDa})$ is found in rat $\mathrm{Nb} 2 \mathrm{~T}$ lymphoma cells and results from an in-frame truncation in the cytoplasmic domain. Several intermediate PRL-R forms with varying 
cytoplasmic domains have been reported in human mammary as well as prostate tumors but their functional significance remains unclear (Clevenger et al., 1995). The intermediate Nb2 PRL-R is more potent than the long PRL-R in both mitogenic (Yu-Lee et al., 1998) and lactogenic (Goffin et al., 1999) signaling. The short PRL-R is suggested to modulate the activity of the long or $\mathrm{Nb} 2 \mathrm{PRL}-\mathrm{R}$ by engaging them in heterodimer complex formation, thereby modulating their signaling capacity (O'Neal and Yu-Lee, 1994; Goffin et al., 1999). Whether the short PRL-R has independent functions is unclear. In Nb2 T cells, where PRL-R is abundant (12,000 PRL-R/cell), only $30 \%$ occupancy of surface PRL-R is needed to elicit maximal proliferative response (Gertler, 1997).

\section{Receptor Motifs}

Several motifs in the PRL-R intracellular domain are important for signal transduction. A proline-rich motif (I-F-P-P-V-P-X-P) proximal to the transmembrane domain is critical for interacting with the protein tyrosine kinase (PTK) Janus activating kinase 2 (JAK2) (Goffin et al., 1999). Upon receptor dimerization and JAK2 activation, several receptor tyrosine residues are phosphorylated, presumably by JAK2. Phosphorylated receptor tyrosine residues provide 'docking sites' for the binding of src homology domain 2 (SH2)-containing proteins, including Stat1, -3, and -5; phosphatases; and other adaptor molecules (Shuai, 2000). In the Nb2 PRL-R, the last tyrosine Y382 or its equivalent Y580 in the long PRL-R is important for signaling via Stat5 (Goffin et al., 1999), while both Y309 and Y382 are needed for signaling via Stat1 to an immediate earlyresponse gene IRF-1 (Wang et al., 1997).

\section{PRL-R-interacting Proteins}

Using the intracellular domain of the PRL-R in a genetic screen, we isolated an enzyme, $2^{\prime} 5^{\prime}$-oligodenylate synthetase (OAS), as a PRL-R-interacting protein (McAveney et al., 2000). Interestingly, OAS is acting more as an adaptor molecule than as an enzyme involved in regulating RNA metabolism. In this unconventional capacity, OAS interaction with the PRL-R reduces Stat1 phosphorylation and DNA-binding activity, which leads to a reduction in IRF-1 promoter activity. In contrast, OAS increases Stat5 DNA binding and $\beta$-casein promoter activity (McAveney et al., 2000). Thus, OAS interaction with the PRL-R enhances PRL-mediated differentiated functions. Consistent with this observation, IFN $\tau$-inducible OAS expression is correlated with increased Stat5mediated differentiated functions in the pregnant ovine endometrium (Johnson et al., 2001). 


\section{B. PROLACTIN-INDUCIBLE KINASE PATHWAYS}

\section{JAK/Stat Pathway}

The best-described signaling pathway activated by PRL is the JAK/Stat pathway (Schindler, 1999) that is commonly used by hematopoietin/cytokine receptors. JAK2 is prebound to the inactive PRL-R monomer, in contrast to other cytokine receptors where JAK PTKs are recruited into the receptor complex upon ligand binding (Yu-Lee and Jeay, 2001). Upon PRL binding and PRL-R homodimerization, JAK2 becomes activated and further phosphorylates downstream targets, including tyrosine residues on the PRL-R itself and Stat factors (Goffin et al., 1999). Stat1, -3, and -5 are activated by tyrosine phosphorylation to form homo- (Stat1/1, Stat3/3, Stat5/5) or heteromeric (Stat1/3) complexes, translocate into the nucleus, bind to conserved DNA elements called interferon (IFN) gamma-activated sequence (GAS), and regulate gene transcription. Since all of the components along the JAK/Stat pathway pre-exist in the cytoplasm, PRL-R signaling is initiated within 1-5 minutes by a series of phosphorylation events. PRL-inducible transcription of target genes is detected in the nucleus within 5-10 minutes.

\section{Parallel Kinase Cascades}

Other PTKs are activated by PRL stimulation, including Fyn, Src, Ras, and Raf, as well as serine/threonine kinases such as ZAP-70, PI3 kinase, Akt, mitogen-activated protein kinase (MAPK), jun kinase (JNK), and protein kinase $\mathrm{C}$ (Clevenger and Kline, 2001). Coordination of parallel kinase cascades with the JAK/Stat signaling pathway likely determines specific patterns of gene expression in various PRL-responsive cells and tissues. The pleiotropic actions of PRL on cellular proliferation, differentiation, apoptosis, or cell survival will depend on the interactions among these parallel kinase cascades.

\section{PRL-inducible Signaling Molecules}

\section{A. STAT FACTORS}

Stat factors are a family of latent cytoplasmic transcription factors that mediate signaling from cytokine receptors (Horvath, 2000; Shuai, 2000). Seven mammalian Stat genes (Stat1-4, -5a, -5b, and -6) have been identified, each encoding a protein $\approx 750-800$ amino acids in size with conserved functional domains. These include a coiled-coiled domain; DNA-binding domain; linker domain; SH2, a critical tyrosine residue that is important for dimerization, nuclear translocation, and DNA binding; and a carboxyl-terminus transactivation domain (Horvath, 2000). Additional post-translational modification - such as 
serine phosphorylation (Decker and Kovarik, 1999; Kovarik et al., 2001), methylation (Mowen et al., 2001), and acetylation (Shankaranarayanan et al., 2001) - further contribute to the ability of Stat factors to regulate gene transcription. Stat $1,-3,-5 a,-5 b$, and -6 have naturally occurring splice variants in the carboxyl terminus, generating dominant-negative $\beta$ isoforms that can bind DNA but lack intrinsic transactivation activity (Horvath, 2000). Stat factors utilize various domains to interact/cross talk with a diverse set of proteins, to transduce signals from the cytoplasm into the nucleus and to regulate gene transcription.

\section{B. STATS INTERACT WITH CYTOPLASMIC PROTEINS}

In addition to interacting with components of the cytokine receptor complex, Stats can interact directly with JAK PTK. The coiled-coil domain of Stats (except Stat2) can interact with the cytoplasmic N-myc interacting protein (Nmi) (Zhu et al., 1999), forming a Stat/Nmi complex that enhances Stat transactivation potentials. Other Stat-interacting proteins include Stat3-interacting protein (StIP1), which interacts with both JAK2 and Stat3 (Collum et al., 2000), and protein inhibitor of activated Stats (PIAS) (Shuai, 2000), which downregulates Stat transcriptional activity. Stats also can interact with Src, in one case as an adaptor molecule (Pfeffer et al., 1997) and in another to potentiate Src-mediated cytoskeletal changes in transiently transfected cells (Kabotyanski and Rosen, 2002). Further, in addition to monomers, dimers, and tetramers, Stats can be found in large (i.e., 1- to 4-MDa) cytoplasmic 'statosome' complexes (Sehgal, 2000), which are thought to contain accessory molecules that facilitate Stat recruitment to the receptor complex as well as Stat translocation into the nucleus. Stat1 also interacts in the cytoplasm with the nuclear transport importin $\alpha / \beta$ complex for transport into the nucleus (Sekimoto et al., 1997). Thus, in the cytoplasm, Stats interact with numerous proteins and acquire signal-transducing capability.

\section{STATS INTERACT WITH NUCLEAR PROTEINS}

Activated Stat complexes translocate into the nucleus within minutes (Horvath, 2000). Once in the nucleus, Stats interact with nuclear proteins, bind to cognate DNA elements (interferon-stimulated response elements (ISRE) or GAS), and regulate gene transcription. The transactivation potentials of Stats are modulated by interactions with nuclear proteins such as $\mathrm{p} 48$ (a member of the IRF family), IRF-1, c-jun, Sp1, Src, nuclear hormone receptors, MCM5 and BRCA1 (Chatterjee-Kishore et al., 2000; Horvath, 2000; Shuai, 2000), and with various coactivators (Collingwood et al., 1999). Coactivators not only facilitate interactions of transcription factors with components of the basal transcription machinery but many coactivators also exhibit intrinsic histone acetyltransferase (HAT) activities, which modify histones and remodel chromatin at promoters, 
resulting in transcriptional activation of genes. Stat1 interacts with three regions within the coactivator protein cyclic AMP response binding protein (CBP)/p300 (Horvath, 2000). Interestingly, one of these regions also interacts with Stat5, leading to the speculation that Stat5 competition with Stat1 for binding to $\mathrm{CBP} / \mathrm{p} 300$ forms one basis for competitive interactions between these two Stats at target promoters (Collingwood et al., 1999; Luo and Yu-Lee, 2000). Thus, coactivators can integrate the activities of DNA-binding proteins to activate gene transcription or can be a target of competitive binding between nuclear factors, which may inhibit gene transcription.

\section{Prolactin Regulation of IRF-1 Transcription}

As one approach to understanding PRL action in the immune system, we cloned a panel of immediate early-response genes from a rat T-lymphoma cell line, $\mathrm{Nb} 2$. One of these genes is the transcription factor IRF-1 (Yu-Lee et al., 1990). IRF-1 is an important immune response mediator. Its regulation by PRL may elucidate a role for PRL in modulating the immune response.

\section{A. IRF-1 AND IMMUNITY}

IRF-1 belongs to a small family of nine IRF proteins (Sato et al., 2000). IRF-1 regulates the expression of a number of genes important for mediating antiviral and antibacterial responses, T-helper 1 immune responses, macrophage and dendritic cell function, NK-cell differentiation, cell-cycle progression, and apoptosis (Taniguchi et al., 2001). Thus, IRF-1 plays an important role in mediating host immune defense. In humans, IRF-1 mutations and/or deletions are correlated with a high incidence of leukemias and myelodysplasia (Taniguchi et al., 2001), suggesting that IRF-1 is a tumor suppressor gene. In view of the diverse functions of IRF-1, its unique response to PRL stimulation (Yu-Lee et al., 1990; Stevens et al., 1995), and the ubiquitous expression of the PRL-R on immune function cells (Goffin et al., 1999; Matera et al., 2001), we suggest that PRL, through the JAK/Stat/IRF-1 pathway, modulates the biological activities of many cell types and tissues as well as aspects of the immune response ( $\mathrm{Yu}-\mathrm{Lee}$ et al., 1998).

\section{B. POSITIVE SIGNALING TO IRF-1}

Consistent with its multifunctional role in mediating diverse immunological functions, IRF-1 expression is regulated by a wide variety of signals (Taniguchi et al., 2001). PRL stimulates IRF-1 gene expression in normal rat leukocytes derived from the bone marrow and spleen (Dogusan et al., 2000) and in human granulocytes (Dogusan et al., 2001). In rat Nb2 T cells, PRL stimulates IRF-1 gene transcription in a distinct manner over the cell cycle, with a transient but 
dramatic 25-fold induction during early G1 and a second peak of induction at the G1/S transition (Stevens et al., 1995). PRL-inducible G1 transcriptional response is mediated by at least three factors assembled at the IRF-1 promoter: inducible Stat1 binding to a GAS element at -120 bp (Stevens et al., 1995), constitutive Sp1 binding at $-200 \mathrm{bp}$ (McAlexander and Yu-Lee, 2001b), and protein-protein interaction between Stat 1 and the coactivator CBP/p300 (Luo and Yu-Lee, 2000) (Figure 1A). Our working model is that, upon PRL stimulation, activated Stat1 binds to the IRF-1 GAS. Together with the pre-bound Sp1, it forms an enhanceosome (assembly of transcription factors) (Carey, 1998), which recruits coactivators such as $\mathrm{CBP} / \mathrm{p} 300$ and cofactor required for Sp1 (CRSP) (Ryu et al., 1999), as well as the general transcription machinery for transcriptional activation of the IRF-1 gene. Additionally, chromatin modification has been shown to play an important role in transcriptional regulation. By using chromatin immunoprecipitation (ChIP) assays, more acetylated histone $\mathrm{H} 4$ is found to associate with the IRF-1 promoter, indicating a more 'active' chromatin conformation in response to PRL stimulation, concomitant with the increase in IRF-1 gene transcription during G1 (McAlexander and Yu-Lee, 2001a). Thus, a combination of factors - including PRL-inducible Stat1, constitutively bound Sp1, and coactivators with their associated chromatin remodeling HAT activities - coordinate PRL stimulation of IRF-1 gene transcription in vivo.

\section{NEGATIVE SIGNALING TO IRF-1}

Much less is known about signals that shut off IRF-1 gene transcription. In $\mathrm{Nb} 2 \mathrm{~T}$ cells, PRL also activates Stat5 to bind as a minor component in the G1 PRL-inducible IRF-1 GAS complex (Wang and Yu-Lee, 1996). Surprisingly, the functional consequence of Stat5 interaction at the IRF-1 promoter is one of transcriptional repression rather than transcriptional activation (Luo and $\mathrm{Yu}-\mathrm{Lee}$, 1997,2000). Stat5 does not interact directly with Stat1 (Greenlund et al., 1995) nor does Stat5 compete with Stat1 for binding to the IRF-1 GAS. In transient transfection studies, Stat5 appears to compete with Stat1 for the coactivator p300/CBP via protein/protein interactions to inhibit PRL signaling to the IRF-1 promoter (Figure 1B) (see Section VI). However, the in vivo mechanism involved in Stat5-mediated negative signaling to the IRF-1 gene is unclear. In vivo, Stat5 can act as a transcriptional repressor. In Stat5a/Stat5b double KO mice, 'increased expression' of genes, including the IRF-1 gene (T. Teixeira, unpublished results), has been observed. This suggests that Stat5 normally represses these genes in vivo (Teglund et al., 1998). In the virgin and early pregnant mammary gland, a high level of Stat1 tyrosine phosphorylation (Liu et al., 1996) correlates with elevated IRF-1 gene expression. In contrast, in the late pregnant and fully differentiated lactating gland, a high level of activated Stat5 is correlated with the complete absence of IRF-1 gene expression (T. Teixeira, 
A. Positive signaling to IRF-1

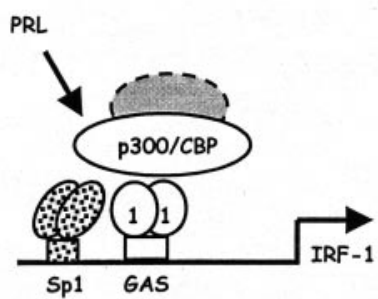

B. Negative signaling to IRF-1

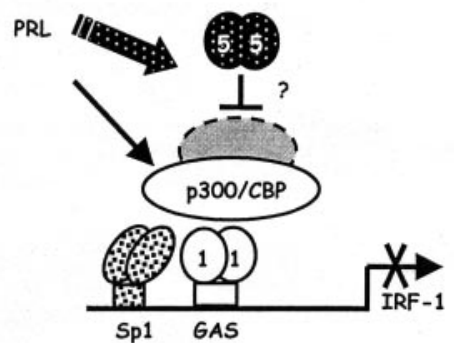

C. Stat1 and NFKB synergy

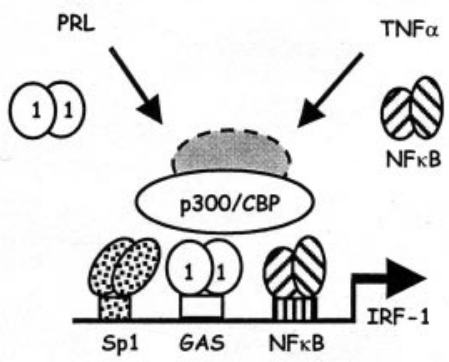

FIG. 1. Model of positive and negative signaling to the interferon regulatory factor-1 (IRF-1) gene. (A) A number of mediators positively regulate prolactin (PRL) stimulation of IRF-1 gene transcription. These include PRL-inducible Stat1, the constitutive factor Sp1, and the coactivator p300/CBP, which enhances Stat1 activation of the IRF-1 promoter. (B) PRLinducible Stat5 inhibits IRF-1 transcription. Although competition for the coactivator p300/CBP appears to be involved (Luo and Yu-Lee, 1997,2000), the in vivo mechanism of inhibition at the IRF-1 promoter is as yet unclear. (C) The IRF-1 promoter can be activated via PRL-inducible Stat 1 as well as by tumor necrosis factor alpha $(\mathrm{TNF} \alpha)$-inducible nuclear factor kappa B $(\mathrm{NF} \kappa \mathrm{B})$ binding to their respective response elements. In this model of positive and negative cytokine signal cross talk, Stat 1 synergizes with $\mathrm{NF} \kappa \mathrm{B}$ but Stat 5 antagonizes NF $\kappa \mathrm{B}$ signaling to the IRF-1 promoter. Additional factors that can be recruited by Stats or $\mathrm{NF} \kappa \mathrm{B}$ to regulate IRF-1 promoter activity are indicated in gray.

unpublished observations). These observations support our model that PRLinducible Stat5 is involved in negative signaling to the IRF-1 promoter. Other mechanisms for transcriptional shutoff may exist, such as PRL-inducible Stat5 activating a repressor to shut off IRF-1 gene transcription. In this regard, the PRL-inducible suppressors of cytokine signaling (SOCS) proteins can bind to the 
PRL-R and turn off signaling at the receptor level in a negative-feedback loop (Naka et al., 1999; Tam et al., 2001).

Interestingly, fewer acetylated histones are associated with the IRF-1 promoter at 4 hours after PRL stimulation, when the transcriptional activity of the IRF-1 gene has returned to baseline (McAlexander and Yu-Lee, 2001a). Thus, a less-active chromatin conformation at the IRF-1 promoter is associated with transcriptional inactivity at the IRF-1 gene. Whether Stat5, co-repressors, and/or histone deacetylase (HDAC) activities are involved in IRF-1 transcriptional shutoff is currently unknown. Our studies show a correlation between the pattern of histone acetylation/deacetylation and biphasic transcription of the IRF-1 gene, implicating histone modification and changes in chromatin structure in PRL regulation of the IRF-1 gene transcription in vivo.

\section{Stat5 and NF $\kappa B$ Cross Talk}

\section{A. NF $\kappa$ B SIGNALING}

The generality of Stat5 acting as a transcriptional inhibitor at the IRF-1 promoter is further illustrated by showing that Stat5 inhibits other signaling molecules that also activate the IRF-1 promoter. One such molecule is NF $\kappa \mathrm{B}$. $\mathrm{NF} \kappa \mathrm{B}$ initially was identified as a nuclear factor that binds to the immunoglobulin kappa light chain gene enhancer in B cells. It is now known to be widely distributed in all cell types (Israel, 2000; Baldwin, 2001). NF $\kappa \mathrm{B}$ was the first transcription factor family shown to reside basally in the cytoplasm but, upon stimulation, translocates into the nucleus to regulate gene transcription. $\mathrm{NF} \kappa \mathrm{B}$ is comprised of several members, including p65/RelA, RelB, c-Rel, p50, and p52. The most abundant form of $\mathrm{NF} \kappa \mathrm{B}$ is a heterodimer of $\mathrm{p} 50 / \mathrm{p} 65$, which is inducible by a wide variety of signals. In unstimulated cells, $\mathrm{NF} \kappa \mathrm{B}$ is sequestered in a complex with its inhibitor $\mathrm{I} \kappa \mathrm{B}$ (Israel, 2000). Upon activation, $\mathrm{NF} \kappa \mathrm{B}$ is released through $\mathrm{I} \kappa \mathrm{B}$ turnover, a process that involves $\mathrm{I} \kappa \mathrm{B}$ phosphorylation, ubiquitination, and degradation via the proteasome pathway. Once in the nucleus, $\mathrm{NF} \kappa \mathrm{B}$ interacts with multiple factors and the basal transcription machinery to regulate gene transcription.

\section{B. STAT5 ANTAGONIZES NFкB SIGNALING}

In addition to the $\mathrm{Sp} 1$ and GAS elements that mediate positive PRL signaling, an NF $\kappa \mathrm{B}$ site mediates TNF $\alpha$ induction of the IRF-1 promoter (Figure 1C). PRL-inducible Stat1 synergizes with $\mathrm{TNF} \alpha$-inducible $\mathrm{NF} \kappa \mathrm{B}$ to activate the IRF-1 promoter (Luo and Yu-Lee, 2000). In contrast, PRL-inducible Stat5 inhibits NF $\kappa \mathrm{B}$-mediated signaling to the IRF-1 promoter. Additionally, PRLinducible Stat5 potently inhibits $\mathrm{NF} \kappa \mathrm{B}$-mediated signaling to promoters that 
contain only $\mathrm{NF} \kappa \mathrm{B}$ binding sites. This observation is significant, as it greatly expands potential targets of Stat5 regulation - in particular, Stat5 inhibition. Interestingly, negative cross talk between Stat5 and $\mathrm{NF} \kappa \mathrm{B}$ is reciprocal in the mammary gland, as $\mathrm{NF} \kappa \mathrm{B}$ inhibits milk protein $\beta$-casein gene expression

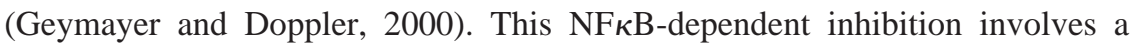
reduction in Stat5 tyrosine phosphorylation in the pregnant gland. We speculate that during mammary gland development, Stat 1 and $\mathrm{NF} \kappa \mathrm{B}$ synergize to activate the IRF-1 gene in the virgin and early pregnant gland, while in the lactating gland, Stat5 coupled with a significant reduction in NF $\kappa \mathrm{B}$ levels prevents IRF-1 expression but maximally induces $\beta$-casein expression. To confirm our model of positive and negative signaling to the IRF-1 promoter, ChIP assays employing antibodies against Stat1, Stat5, p300 coactivator, and perhaps co-repressors will be used to identify which factors are recruited to the IRF-1 promoter in response to PRL stimulation in a temporally distinct manner to regulate IRF-1 gene transcription in vivo.

\section{Positive and Negative Regulation by Stats}

In addition to the well-described functions of Stats as positive mediators of cytokine signaling, several lines of evidence now show that Stats can function as transcriptional repressors. Stat1 has been shown to mediate IFN $\gamma$-dependent activation or repression of target genes (Ramana et al., 2000). In Stat5a/Stat5bdeficient mice, the expression of some Stat 5 target genes is found to be elevated, suggesting a relief of Stat5-mediated repression in vivo (Teglund et al., 1998). These findings support the physiological relevance of our observation that Stat5 acts as a transcriptional repressor at the IRF-1 promoter (Luo and Yu-Lee, 2000). Whether Stat5 is acting directly or through a Stat5-inducible factor to repress IRF-1 gene transcription is yet to be determined. We speculate that negative cross talk between Stat5 and NF $\kappa$ B, Smad, or glutocorticoid receptor (GR) could, in part, explain how PRL antagonizes $\operatorname{TNF} \alpha$, TGF $\beta$, or glucocorticoid signaling, respectively, at target genes. It is now known that conformational changes induced by ligand binding to nuclear hormone receptors, coupled with the levels of coactivators or co-repressors present, determine the biological activities of the receptor complex on target gene transcription (e.g., by changing an estrogen antagonist into an agonist) (Lavinsky et al., 1998; McDonnell, 1999). While the mechanistic details are still unclear, transcriptional regulation by Stats is a complex process. Stats can act as transcriptional activators or transcriptional repressors, depending on the promoter context, the concentrations of available coactivators and co-repressors, the presence of other DNA-binding proteins, and the stage of differentiation of the target cell and tissue. 


\section{Concluding Remarks}

PRL is a versatile neuroendocrine hormone that also works as a locally produced cytokine. In this capacity, PRL regulates a wide range of physiological responses and a correspondingly wide range of target genes. A large panel of PRL-inducible genes in proliferating $\mathrm{Nb} 2 \mathrm{~T}$ cells has been identified (BoleFeysot et al., 2000). A handful of other genes has been studied to understand PRL-mediated differentiative functions and cell survival responses. Interestingly, a recent study shows fine differences in PRL signaling in different populations of blood leukocytes (Dogusan et al., 2001). PRL activates Stat5 and SOCS3 in peripheral blood mononuclear cells, while PRL activates Stat1 and SOCS2 in human granulocytes. Whether this difference in initial signaling components and target gene activation translates into functional differences in PRL action in these two leukocyte populations remains to be determined. At present, the details of what regulates the qualitative differences in PRL signaling are not understood. It is likely that a combination of steady-state levels, availability and activation of Stats, the levels of coactivators and co-repressors, and even the type of SOCS proteins induced by PRL (Tam et al., 2001) contributes to the tissue-specific or cell-type specific responses to PRL. The challenge is to identify and quantify these differences at the gene and protein levels. A further challenge is to analyze these differences in the context of normal versus pathological states. Future studies will employ a wide variety of approaches to fill in this gap in knowledge. These include DNA microarray; ChIP assays; transgenics overexpressing PRL or mice deficient in PRL, PRL-R, Stat5a, Stat5b or Stat5a/Stat5b; and proteomic technologies. Crossing the PRL-R KO with autoimmune disease strains of mice, for example, will better elucidate how PRL functions as a homeostatic molecule in modulating immune, autoimmune, and inflammatory responses.

\section{ACKNOWLEDGMENTS}

I would like to acknowledge the contributions of past and present members of my laboratory and, in particular, Therese Teixeira for the unpublished data discussed in this review, Nelson Horseman for communicating prepublication information, and Jeff Rosen and Sophia Tsai for critical comments. This work is supported by grants from the National Institutes of Health, Linda and Ronald Finger Lupus Research Center, and Women's Fund for Health, Education and Research.

\section{REFERENCES}

Ahonen T, Harkonen PL, Laine J, Rui H, Martikainen PM, Nevalainen MT 1999 Prolactin is a survival factor for androgen-deprived rat dorsal and lateral prostate epithelium in organ culture. Endocrinology 140:5412-5421

Baldwin AS 2001 Control of oncogenesis and cancer therapy resistance by the transcription factor NF-kappaB. J Clin Invest 107:241-246 
Bellone G, Geuna M, Carbone A, Silvestri S, Foa R, Emanuelli G, Matera L 1995 Regulatory action of prolactin on the in vitro growth of $\mathrm{CD} 34+$ ve human hemopoietic progenitor cells. J Cell Physiol 163:221-231

Ben-Jonathan N, Mershon J, Allen D, Steinmetz R 1996 Extrapituitary prolactin: distribution, regulation, functions and clinical aspects. Endocr Rev 17:639-669

Bole-Feysot C, Goffin V, Edery M, Binart N, Kelly PA 1998 Prolactin (PRL) and its receptor: actions, signal transduction pathways and phenotypes observed in PRL receptor knockout mice. Endocr Rev 19:225-268

Bole-Feysot C, Perret E, Roustan P, Bouchard B, Kelly PA 2000 Analysis of prolactin-modulated gene expression profiles during the $\mathrm{Nb} 2$ cell cycle using differential screening techniques. Genome Biol 1:research0008.1-0008.15

Bouchard B, Ormandy CJ, Di Santo JP, Kelly PA 1999 Immune system development and function in prolactin receptor-deficient mice. J Immunol 163:576-582

Buckley AR 2001 Prolactin, a lymphocyte growth and survival factor. Lupus 10:684-690

Carey M 1998 The enhanceosome and transcriptional synergy. Cell 92:5-8

Chatterjee-Kishore M, Wright KL, Ting JPY, Stark GR 2000 How Stat1 mediates constitutive gene expression: a complex of unphosphorylated Stat1 and IRF1 supports transcription of the LMP2 gene. EMBO J 19:4111-4122

Clevenger CV, Kline BJ 2001 Prolactin receptor signal transduction. Lupus 10:706-718

Clevenger CV, Chang WP, Ngo W, Pasha TLM, Montone KT, Tomaszweski JE 1995 Expression of prolactin and prolactin receptor in human breast carcinoma. Am J Pathol 146:695-705

Collingwood TN, Urnov FD, Wolffe AP 1999 Nuclear receptors: coactivators, corepressors and chromatin remodeling in the control of transcription. J Mol Endocrinol 23:255-275

Collum RG, Brutsaer S, Lee G, Schindler C 2000 A Stat3 interacting protein (StIP1) regulates cytokine signal transduction. Proc Natl Acad Sci USA 97:10120-10125

Couse JF, Korach KS 1999 Estrogen receptor null mice: what have we learned and where will they lead us? Endocr Rev 20:358-417

Deb S, Tessier C, Prigent-Tessier A, Barkai U, Ferguson-Gottschall S, Srivastava RK, Faliszek J, Gibori G 1999 The expression of interleukin-6 (IL-6), IL-6 receptor, and gp130 kDa glycoprotein in the rat decidua and a decidual cell line: regulation by $17 \beta$-estradiol and prolactin. Endocrinology 140:4442-4450

Decker T, Kovarik P 1999 Transcription factor activity of Stat proteins: structural requirements and regulation by phosphorylation and interacting proteins. Cell Mol Life Sci 55:1535-1546

DeVito WJ, Okulicz WC, Stone S, Avakian C 1992 Prolactin-stimulated mitogenesis of cultured astrocytes. Endocrinology 130:2549-2556

Dogusan Z, Book ML, Verdood P, Yu-Lee Ly, Hooghe-Peters E 2000 Prolactin activates interferon regulatory factor- 1 expression in normal lympho-hemopoietic cells. Eur Cytokine Netwk 11:435-442

Dogusan Z, Hooghe R, Verdood P, Hooghe-Peters EL 2001 Cytokine-like effects of prolactin in human mononuclear and polymorphonuclear leukocytes. J Neuroimmunol 120:58-66

Dorshkind K, Horseman ND 2000 The roles of prolactin, growth hormone, insulin-like growth factor-I, and thyroid hormones in lymphocyte development and function: insights from genetic models of hormone and hormone receptor deficiency. Endocr Rev 21:292-312

Dorshkind K, Horseman ND 2001 Anterior pituitary hormones, stress, and immune system homeostasis. BioEssays 23:2881793-2941803

Gertler A 1997 Recombinant analogues of prolactin, growth hormone, and placental lactogen: correlations between physical structure, binding characteristics, and activity. J Mamm Gland Biol Neoplasia 2:69-80 
Geymayer S, Doppler W 2000 Activation of $\mathrm{NF}_{\kappa} \mathrm{B}$ p50/p65 is regulated in the developing mammary gland and inhibits Stat5-mediated $\beta$-casein gene expression. FASEB J 14:11591170

Girasole G, Jilka RL, Passeri G, Boswell S, Boder G, Williams DC, Manolagas SC 1992 $17 \beta$-estradiol inhibits interleukin- 6 production by bone marrow-derived stromal cells and osteoblasts in vitro: a potential mechanism for the antiosteoporotic effect of estrogens. J Clin Invest 89:883-891

Goffin V, Kelly PA 1997 The prolactin/growth hormone receptor family: structure/function relationships. J Mamm Gland Biol Neoplasia 2:7-17

Goffin V, Binart N, Clement-Lacroix P, Bouchard B, Bole-Feysot C, Edery M, Lucas BK, Touraine P, Pezet A, Maaskant R, Pichard C, Helloco C, Baran N, Favre H, Bernichtein S, Allamando A, Ormandy C, Kelly PA 1999 From the molecular biology of prolactin and its receptor to the lessons learned from knockout mice models. Genet Anal Biomol Engin 15:189-201

Gout PW, Beer CT, Noble RL 1980 Prolactin-stimulated growth of cell cultures established from malignant $\mathrm{Nb}$ rat lymphomas. Cancer Res 40:2433-2436

Greenlund AC, Morales MO, Viviano BL, Yan H, Krolewski J, Schreiber RD 1995 Stat recruitment by tyrosine-phosphorylated cytokine receptors: an ordered reversible affinitydriven process. Immunity 2:677-687

Grimaldi CM, Michael DJ, Diamond B 2001 Cutting edge: expansion and activation of a population of autoreactive marginal zone B cells in a model of estrogen-induced lupus. J Immunol 167:1886-1890

Harris MT, Feldberg RS, Lau KM, Lazarus NH, Cochrane DE 2000 Expression of proinflammatory genes during estrogen-induced inflammation of the rat prostate. Prostate 44:19-25

Hooghe R, Dogusan Z, Martens N, Velkeniers B, Hooghe-Peters EL 2001 Effects of prolactin on signal transduction and gene expression. Possible relevance for systemic lupus erythematosus. Lupus 10:719-727

Horseman, ND 2001 Prolactin. Boston: Kluwer Academic Publishers

Horseman ND, Zhao W, Montecino-Rodriguez E, Tanaka M, Nakashima K, Eagle SJ, Smith F, Markoff E, Dorshkind K 1997 Defective mammopoiesis, but normal hematopoiesis, in mice with a targeted disruption of the prolactin gene. EMBO J 16:6926-6935

Horvath CM 2000 Stat proteins and transcriptional responses to extracellular signals. Trends Biochem Sci 25:496-502

Israel A 2000 The IKK complex: an integrator of all signals that activate NF-kappaB? Trends Cell Biol 10:129-133

Jacobi AM, Rohde W, Volk HD, Dorner T, Burmester GR, Hiepe F 2001 Prolactin enhances the in vitro production of $\mathrm{IgG}$ in peripheral blood mononuclear cells from patients with systemic lupus erythematosus but not from healthy controls. Ann Rheum Dis 60:242-247

Jarrar D, Wang P, Knoferl MW, Kuebler JF, Cioffi WG, Bland KI, Chaudry IH 2000 Insight into the mechanism by which estradiol improves organ functions after trauma-hemorrhage. Surgery 128:246-252

Johnson AG, Stewart D, Choi Y, Burghardt RC, Yu-Lee Ly, Chebath J, Bazer FW, Spencer TE 2001 Effects of the estrous cycle, pregnancy and interferon $\tau$ on $2^{\prime}, 5^{\prime}$-oligoadenylate synthetase expression in the ovine uterus. Biol Reprod 64:1392-1399

Kabotyanski E, Rosen JM 2002 Signal transduction pathways regulated by prolactin and Src result in different conformations of activated Stat5b. J Biol Chem, in press

Kanik KS, Wilder RL 2000 Hormonal alterations in rheumatoid arthritis, including the effects of pregnancy. Neuroendocr Mech Rheum Dis 26:805-823 
Knoferl MW, Diodato MD, Angele MK, Ayala A, Cioffi WG, Bland KI, Chaudry IH 2000a Do female sex steroid adversely or beneficially affect the depressed immune responses in males after trauma-hemorrhage? Arch Surg 135:425-433

Knoferl MW, Angele MK, Ayala A, Cioffi WG, Bland KI, Chaudry IH 2000b Insight into the mechanism by which metoclopramide improves immune functions after trauma-hemorrhage. Am J Physiol Cell Physiol 279:C72-C80

Kooijman R, Hooghe-Peters EL, Hooghe R 1996 Prolactin, growth hormone, and insulin-like growth factor-1 in the immune system. Adv Immunol 63:377-454

Kovarik P, Mangold M, Ramsauer K, Heidari H, Steinborn R, Zotter A, Levy DE, Muller M, Decker T 2001 Specificity of signaling by Stat 1 depends on SH2 and C-terminal domains that regulate Ser727 phosphorylation, differentially affecting specific target gene expression. EMBO J 20:91-100

Kurebayashi S, Miyashita Y, Hirose T, Kasayama S, Akira S, Kishimoto T 1997 Characterization of mechanisms of interleukin- 6 gene repression by estrogen receptor. J Steroid Biochem Molec Biol 60:11-17

Lavinsky RM, Jepsen K, Heinzel T, Torchia J, Mullen TM, Schiff R, Del-Rio AL, Rocote, Ngo S, Gemsch J, Hilsenbeck SG, Osborne CK, Glass CK, Rosenfeld MG, Rose DW 1998 Diverse signaling pathways modulate nuclear receptor recruitment of N-CoR and SMRT complexes. Proc Natl Acad Sci USA 95:2920-2925

LaVoie HA, Witorsch RJ 1995 Investigation of intracellular signals mediating the anti-apoptotic action of prolactin in Nb2 lymphoma cells. Proc Soc Exp Biol Med 209:257-269

Leav I, Merk FB, Lee KF, Loda M, Mankoki M, McNeal JE, Ho S-M 1999 Prolactin receptor expression in the developing human prostate and in hyperplastic, dysplastic, and neoplastic lesions. Am J Pathol 154:863-870

Lin DL, Whitney MC, Yao Z, Keller ET 2001 Interleukin-6 induces androgen responsiveness in prostate cancer cells through up-regulation of androgen receptor expression. Clin Cancer Res 7:1773-1781

Lin J, Linzer DIH 1999 A novel megakaryocyte differentiation factor from mouse placenta. Trends Cardiovasc Med 9:167-171

Liu X, Robinson GW, Hennighausen L 1996 Activation of Stat5a and Stat5b by tyrosine phosphorylation is tightly linked to mammary gland differentiation. Mol Endocrinol 10: $1496-1506$

Luo G, Yu-Lee Ly 1997 Transcriptional inhibition by Stat5: differential activities at growth-related versus differentiation-specific promoters. J Biol Chem 272:26841-26849

Luo G, Yu-Lee Ly 2000 Stat5 inhibits NF $\kappa$ B-mediating signaling. Mol Endocrinol 14:114-123

Manolagas SC 2000 Birth and death of bone cells: basic regulatory mechanisms and implications for the pathogenesis and treatment of osteoporosis. Endocr Rev 21:115-137

Matera L, Mori M, Geuna M 2000 Prolactin in autoimmunity and antitumor defense. J Neuroimmunol 109:47-55

Matera L, Galetto A, Mori M 2001 Effect of prolactin on the antigen presenting function of monocyte-derived dendritic cells. Lupus 10:728-734

McAlexander MB, Yu-Lee Ly 2001a Prolactin activation of IRF-1 transcription involves changes in histone acetylation. FEBS Lett 488:91-94

McAlexander MB, Yu-Lee Ly 2001b Sp1 is required for prolactin activation of the interferon regulatory factor 1 gene. Mol Cell Endocrinol 184:135-141

McAveney KM, Gimble JM, Yu-Lee Ly 1996 Prolactin receptor expression during adipocyte differentiation of bone marrow stroma. Endocrinology 137:5723-5726

McAveney KM, Book ML, Ling P, Horvath G, Chebath J, Yu-Lee Ly 2000 Association of 2 ',5'-oligoadenylate synthetase with the prolactin receptor: alteration in prolactin-inducible Stat1 signaling to the IRF-1 promoter. Mol Endocrinol 14:295-306 
McDonnell DP 1999 The molecular pharmacology of SERMS. Trends Exp Med 10:301-311

McMurray RW 2001 Estrogen, prolactin, and autoimmunity: actions and interactions. Intl Immunopharmacol 1:995-1008

Montgomery DW 2001 Prolactin production by immune cells. Lupus 10:665-675

Morales P, Carretero M, Geronimo H, Copin SG, Gaspar ML, Marcos MA, Martin-Perez J 1999 Influence of prolactin on the differentiation of mouse B-lymphoid precursors. Cell Growth Diff 10:583-590

Morris JA, MacKenzie EJ, Damiano AM, Bass SM 1990 Mortality in trauma patients: the interaction between host factors and severity. J Trauma 30:1476-1482

Morris SM, Anaya P, Xiang X, Morris NR, May GS, Yu-Lee Ly 1997 A prolactin-inducible T cell gene product is structurally similar to the Aspergillus nidulans nuclear movement protein NUDC. Mol Endocrinol 11:229-236

Mowen KA, Tang J, Zhu W, Schurter BT, Shuai K, Herschman HR, David M 2001 Arginine methylation of STAT1 modulates IFNalpha/beta-induced transcription. Cell 104:731-741

Muller H, Liu, Croy BA, Head JR, Hung JS, Dai G, Soares MJ 1999 Uterine natural killer cells are targets for a trophoblast cell-specific cytokine, prolactin-like protein A. Endocrinology 140:2711-2720

Naka T, Fujimoto M, Kishimoto T 1999 Negative regulation of cytokine signaling: Stat-induced Stat inhibitor. Trends Biochem Sci 24:394-398

Nanbu-Wakao R, Fujitani Y, Masuho Y, Muramatsu M, Wakao H 2000 Prolactin enhances CCAAT enhancer-binding protein-beta (C/EBP beta) and peroxisome proliferator-activated receptor gamma (PPAR gamma) messenger RNA expression and stimulates adipogenic conversion of NIH-3T3 cells. Mol Endocrinol 14:307-316

Nevalainen MT, Valve EM, Ahonen T, Yagi A, Paranko J, Harkonen PL 1997 Androgendependent expression of prolactin in rat prostate epithelium in vivo and in organ culture. FASEB J 11:1297-1307

O'Neal KD, Yu-Lee Ly 1994 Differential signal transduction of the short, Nb2, and long PRL receptor: activation of IRF-1 and cell proliferation. J Biol Chem 269:26076-26082

Oberholzer A, Keel M, Zellweger R, Steckholzer U, Trentz O, Ertel W 2000 Incidence of septic complications and multiple organ failure in severely injured patients is sex specific. J Trauma: Inj Inf Crit Care 48:932-937

Offner PJ, Moore EE, Biffl WL 1999 Male gender is a risk factor for major infections after surgery. Arch Surg 134:935-940

Ogle CK, Kong F, Guo X, Wells DA, Aosasa S, Noel G, Horseman ND 2000 The effect of burn injury on suppressors of cytokine signaling. Shock 14:392-398

Peeva E, Grimaldi C, Spatz L, Diamond B 2000 Bromocryptine restores tolerance in estrogentreated mice. J Clin Invest 106:1373-1379

Pfeffer LM, Mullersman JE, Pfeffer SR, Murti A, Yang CH 1997 Stat3 as an adapter to couple phosphatidylinositol 3-kinase to the IFNAR1 chain of the type I interferon receptor. Science 276:1418-1420

Ramana CV, Chatterjee-Kishore M, Nguyen H, Stark GR 2000 Complex roles of Stat in regulating gene expression. Oncogene 19:2619-2627

Richards SM, Murphy WJ 2000 Use of human prolactin as a therapeutic protein to potentiate immunohematopoietic function. J Neuroimmunol 109:56-62

Richards SM, Garman RD, Keyes L, Kavanagh B, McPherson JM 1998 Prolactin is an antagonist of TGF- $\beta$ activity and promotes proliferation of murine B cell hybridomas. Cell Immunol 184:85-91

Ryu S, Zhou S, Ladurner AG, Tijan R 1999 The transcriptional cofactor complex CRSP is required for activity of the enhancer-binding protein Sp1. Nature 397:446-450 
Sato M, Taniguchi T, Tanaka N 2000 The interferon system and interferon regulatory factor transcription factors - studies from gene knockout mice. Cytokine Growth Factor Rev $12: 133-142$

Schindler C 1999 Cytokine and Jak-Stat signaling. Exp Cell Res 253:7-14

Sehgal PB 2000 Stat-signaling through the cytoplasmic compartment: consideration of a new paradigm. Cell Signal 12:525-535

Sekimoto T, Imamoto N, Makajima K, Hirano T, Yoneda Y 1997 Extracellular signal-dependent nuclear import of Stat 1 is mediated by nuclear pore targeting complex formation with NPI-1, but not Rch1. EMBO J 16:7067-7077

Shankaranarayanan P, Chaitidis P, Kuhn H, Nigam S 2001 Acetylation by histone acetyltransferases $\mathrm{CBP} / \mathrm{p} 300$ of STAT6 is required for the transcriptional activation of the $15-\mathrm{LOX}-1$ gene. J Biol Chem 276:42753-42760

Shuai K 2000 Modulation of Stat signaling by Stat-interacting proteins. Oncogene 19:2638-2644

Smith P 1930 The effect of hypophysectomy upon the involution of the thymus in the rat. Anatom $\operatorname{Rec}$ 47:119

Stevens AM, Wang Y, Sieger KA, Lu H, Yu-Lee Ly 1995 Biphasic transcriptional regulation of the interferon regulatory factor- 1 gene by prolactin: involvement of gamma-interferon activated sequence and Stat-related proteins. Mol Endocrinol 9:513-525

Stoker TE, Robinette CL, Britt BH, Laws SC, Cooper RL 1999 Prepubertal exposure to compounds that increase prolactin secretion in the male rat: effects on the adult prostate. Biol Reprod 61:1636-1643

Tam SP, Lau P, Djiane J, Hilton DJ, Waters MJ 2001 Tissue-specific induction of SOCS gene expression by PRL. Endocrinology 142:5015-5026

Tangbanluekal L, Robinette CL 1993 Prolactin mediates estradiol-induced inflammation in the lateral prostate of Wistar rats. Endocrinology 132:2407-2416

Taniguchi T, Ogasawara K, Takaoka A, Tanaka N 2001 IRF family of transcription factors as regulators of host defense. Annu Rev Immunol 19:623-655

Teglund S, McKay C, Schuetz E, van Deursen JM, Stravopodis D, Wang D, Brown M, Bodner S, Grosveld G, Ihle JN 1998 Stat5a and Stat5b proteins have essential and nonessential, or redundant, roles in cytokine responses. Cell 93:841-850

Tessier C, Deb S, Prigent-Tessier A, Ferguson-Gottschall S, Gibori GB, Shiu RPC, Gibori G 2000 Estrogen receptors $\alpha$ and $\beta$ in rat decidua cells: cell-specific expression and differential regulation by steroid hormones and prolactin. Endocrinology 141:3842-3851

Thellin O, Noel G, Khurana S, Ogle CK, Horseman ND 2001 Stress hormone secretion and gut signal transducer (Stat) proteins after burn injury in rats. Shock 16:393-397

van Coppenolle F, Slomianny C, Carpentier F, Le Bourhis X, Ahidouchi A, Croix D, Legrand G, Dewailly E, Fournier S, Cousse H, Authie D, Raynaud J, Beauvillain JC, Dupouy JP, Prevarskaya N 2001 Effects of hyperprolactinemia on rat prostate growth: evidence of androgeno-dependence. Am J Physiol Endocrinol Metab 280:E120-E129

Vidaller A, Guadarrama F, Llorente L, Mendez JP, Larrea F, Villa AR, Alarcon-Segovia D 1992 Hyperprolactinemia inhibits natural killer (NK) cell function in vivo and its bromocriptine treatment not only corrects it but makes it more efficient. J Clin Immunol 12:210-215

Walker SE 2001 Bromocriptine treatment of systemic lupus erythematosus. Lupus 10:762-768

Wang Y, Yu-Lee Ly 1996 Multiple Stat complexes interact at the IRF-1 GAS in prolactin-stimulated $\mathrm{Nb} 2 \mathrm{~T}$ cells. Mol Cell Endocrinol 121:19-28

Wang Y, O’Neal KD, Yu-Lee Ly 1997 Multiple prolactin receptor cytoplasmic residues and Stat1 mediate prolactin signaling to the IRF-1 promoter. Mol Endocrinol 11:1353-1364

Wennbo H, Kindblom J, Isaksson EGP, Tornell J 1997 Transgenic mice overexpressing the prolactin gene develop dramatic enlargement of the prostate gland. Endocrinology 138:44104415 
Yamamoto T, Matsuda T, Junicho A, Kishi H, Saatcioglu F, Muraguchi A 2000 Cross-talk between signal transducer and activator of transcription 3 and estrogen receptor signaling. FEBS Lett 486:143-148

Yu-Lee Ly 1997 Molecular actions of prolactin in the immune system. Proc Soc Exp Biol Med 215:35-52

Yu-Lee Ly, Jeay S 2002 Prolactin and growth hormone receptors: signal transduction and cross talk. In: Goffin V, Kelly PA (eds) Hormone Signaling. Norwell, MA: Kluwer Academic Publishers; $121-144$

Yu-Lee Ly, Luo G, Moutoussamy S, Finidori J 1998 Prolactin and growth hormone signal transduction in lymphohemopoietic cells. Cell Mol Life Sci 54:1067-1075

Yu-Lee Ly, Hrachovy JA, Stevens AM, Schwarz LA 1990 Interferon-regulatory factor 1 is an immediate-early gene under transcriptional regulation by prolactin in Nb2 T cells. Mol Cell Biol 10:3087-3094

Zellweger R, Zhu X-H, Wichmann MW, Ayala A, DeMaso CM, Chaudry IH 1996 Prolactin administration following hemorrhagic shock improves macrophage cytokine release capacity and decreases mortality from subsequent sepsis. J Immunol 157:5748-5754

Zhu M, John S, Berg M, Leonard WJ 1999 Functional association of Nmi with Stat5 and Stat1 in IL-2- and IFN $\gamma$-mediated signaling. Cell 96:121-130

Zhu X-H, Zellweger R, Wichmann MW, Ayala A, Chaudry IH 1997 Effects of prolactin and metoclopramide on macrophage cytokine gene expression in late sepsis. Cytokine 9:437-446 